\title{
Are You Out of Your Mind? Focalization in Digital Games
}

Fraser Allison

Transactions of the Digital Games Research Association

2016, Vol. 2, No. 3, pp. 31-60

ISSN 2328-9422

http://todigra.org

TEXT: Licensed under Creative Commons Attribution (CC BY-NC- ND

2.5) http://creativecommons.org/licenses/by-nc- nd/2.5/

IMAGES: All images appearing in this work are property of the respective copyright owners, and are not released into the Creative Commons. The respective owners reserve all rights.

\section{ABSTRACT}

This paper demonstrates how the concept of focalization, as defined by Gérard Genette (1980), can be used to analyze experiences of subjectivity in digital games. Strategies to create internal focalization are identified in games' audiovisual presentation, provision and restriction of private knowledge, and ludic affordances. This provides a framework for games that seek to present diverse or distinctive perspectives, to allow players to access modes of thinking that accord with a mind other than their own. This framework can assist researchers, critics, and designers to identify ways in which digital games express elements of internal 
focalization that communicate the mental patterns of a perspective character.

\section{Keywords}

Focalization, perspective, subjectivity, Mirror's Edge, Grand Theft Auto, The Sims

\section{INTRODUCTION}

In video games, it is typical for the player to be given control of one or more character-avatars that anchor the perspective on the game world. Drawing on cinematic and literary traditions, these characters are commonly provided with well-defined personalities, traits, abilities and motivations. In many cases, the player's viewpoint is literally inside the character's head - and yet rarely does the player know what their character is thinking.

This paper explores instances in which video games convey an experience of subjectivity, utilizing an appropriation of Gérard Genette's (1980) concept of focalization. The purpose is to provide a framework for analysis of designs that seek to present a distinctive perspective: a characteristic way of looking at and understanding the virtual environment, narrative and characters. The framework can assist researchers, critics, and designers to identify ways in which video games express internal focalization by communicating the mental patterns of one or more perspective characters, and can be used as a lens to survey opportunities for creating experiential narratives that allow the player to access modes of thinking that accord with a mind other than their own.

The paper begins with an overview of the contested theory of focalization, and the psychological understanding which informs it: that no two experiences of the same event are exactly alike. It reviews existing applications in video game studies of focalization, and seek to show that there is a greater scope for analysis of this kind than has yet been explored. 
It proposes that focalization is apparent in video games through their audiovisual presentation, their provision and restriction of private knowledge ${ }^{1}$, and their ludic affordances. In particular, ludic affordances provide a degree of internal focalization to all character-based video games, giving the concept wide relevance within game studies and game criticism. An analysis of The Sims 3 (The Sims Studio 2009), Top Spin 4 (2K Czech 2011), Mirror's Edge (EA Digital Illusions CE 2008), Grand Theft Auto V (Rockstar North 2014), Assassin's Creed II (Ubisoft Montreal 2009) and QWOP (Foddy 2008) will show how each of the above channels can convey focalization, identifying opportunities for game designers to communicate the private, subjective experience of being a character with a distinctive worldview.

\section{2: Focalization}

To understand how something appears to a person, it is necessary to consider not only the place from which it is observed, but also the nature of the observer. As the psychologist William James noted: "what is called our 'experience' is almost entirely determined by our habits of attention.” (1892, 156) James illustrated this point with the analogy of four tourists:

"Let four men make a tour in Europe. One will bring home only picturesque impressions - costumes and colors, parks and views and works of architecture, pictures and statues. To another all this will be non-existent; and distances and prices, populations and drainage-arrangements, door- and window-fastenings, and other useful statistics will take their place. A third will give a rich account of the theatres, restaurants, and public halls, and naught besides; whilst the fourth will perhaps have been so wrapped in his own subjective broodings as to be able to tell little more than a few names of places through which he passed. Each has selected, out of the same mass of presented objects, those which suited his private interest and has made his experience thereby." (James 1892, 156-157)

James observed that attention acts as a filter on our experience. Not 
everything that we can physically see or observe enters our conscious experience; attention is also required, and attention is influenced by our mental state and our thinking at the time. This is apparent in the phenomenon of "inattentional blindness", in which people fail to notice seemingly obvious things that are unrelated to the task on which they are focused. The effect has been tested with stimuli as striking as a clown on a unicycle (Hyman et al. 2009) and a person wearing a gorilla suit (Most et al. 2001). Beyond this, differences in knowledge and life experience affect the interpretation of a scene; consider how differently an automobile mechanic makes sense of a car engine than someone who has never peered under a hood, though their eyes see the same things.

The difference between a scene's raw components and its subjective experience has been addressed by the narratologist Gérard Genette (1980). Genette drew a distinction between the position from which a story is told (its narration) and the position from which it is perceived (its focalization). Focalization defines how narrative information is selectively presented relative to the knowledge and experience of one or more characters within the scene. The concept is similar to perspective, but whereas perspective describes the position from which a scene is observed, focalization describes what aspects of the scene can be observed as compared to a character.

Genette proposed three categories of focalization. A narrative with internal focalization presents the inner thoughts, feelings, perceptions or knowledge of a perspective character. A narrative with external focalization presents only what is externally observable, such as characters' speech and behavior. And a narrative with zero focalization is not bounded by any one character's perspective, and presents information beyond what one person could experience - such as the inner thoughts and feelings of multiple characters. Some narratives switch between these modes of focalization.

Consider George R. R. Martin's novel A Game of Thrones (1996) and its television adaptation, Game of Thrones (Benioff and Weiss 2011). Both 
tell essentially the same story, with only minor differences in the events depicted. In both versions, the narrative switches between several perspective characters: we see and hear the events that they see and hear. Yet the focalization differs. The television series is externally focalized, so that we observe the words and actions of the perspective character, but cannot know what they are thinking or feeling. In contrast, the novel is internally focalized, with the perspective characters' thoughts revealed; so we can read of Lady Catelyn Stark's secret resentment towards her husband's bastard son, Jon Snow, which she does not admit to aloud. Thus, in the two versions the story is essentially the same, and the perspective is the same, but the focalization is different.

Genette's concept of focalization has become a core concept in narratology, but not without controversy. Mieke Bal (2009) argued for a significant divergence from Genette by adding the concept of the focalizer. Bal's focalizer is the subject of focalization, the active agent through which the narrative is perceived - the narrative equivalent of a camera lens. This is in contrast with Genette's concept of focalization as a passive property of the text. To Bal, internal and external focalization refer to the position of the focalizer inside or outside the fabula. Bal aligns focalization more closely with perspective, and broadens its application from literary written texts to visual texts, such as films and images. Genette himself (1988) disagreed with many of the proposed changes to his framework, ${ }^{2}$ and the theory remains disputed. Manfred Jahn went so far as to say: "One of the questions that every narratologist has to decide for himself or herself is whether to adopt Genette's or Bal's terms” $(2010,176)$.

In this paper, I use Genette's framework primarily for its utility in exploring how the selection and presentation of information can provide an understanding of the private experience of a character. However, Bal's concept of the focalizer also has application for game studies, particularly with regards to visual presentation (see Nitsche 2005). 


\section{1: Defining terms}

Like a traditional narrative text, a video game experience incorporates several layers of identity and character in the interaction between the user and the text. Before discussing the relationships between these layers of identity that are described by focalization, it is useful to clearly define the terminology. Carter et al. (2012) differentiate four distinct constructs in how players understand the layers of identity in a digital game:

- User: The offline identity of the video game player.

- Player: The socially performed identity of the game player, which persists across play sessions and avatars.

- Character: The fictional identity within the narrative or setting of the virtual world.

- Avatar: The virtual visualization of the character as an entity.

Carter et al.'s terms were drawn from users of a multiplayer online virtual world, in which context the distinction between user and player is more relevant than in the more narrowly constrained single-player games that are the focus here. For the purpose of this paper, "player” is considered to be synonymous with "user", as the real person who operates the controls.

Similarly, the concepts of character and avatar may be tightly bound together in the context of certain games that have a clearly defined and characterized player avatar (such as Mirror's Edge). In other cases, the player may have an avatar without a character (as in Minecraft, Mojang 2009), or a character without an avatar (as in Civilization V, Firaxis Games 2010).

\section{2: Focalization in video game studies}

The concept of focalization has infrequently been appropriated for use in video game studies (Nitsche 2005; Arjoranta 2015), but has broader 
potential for application in both critical analysis and design for portraying the inner experience of a character rather than simply their perspective. Adapting Genette's concept of focalization provides a framework to understand this distinction, and to identify ways in which video games can present players with a manner of thinking that is subjective and foreign to their own - what Ian Bogost has called "another way of looking” (2008, 2). For designers and critics, it provides a terminology to discuss the alignment between characterization in narrative elements and characterization in play, and an analytical tool for designs that seek to facilitate player identification with a character perspective (as discussed in Papale 2014). Successfully creating player identification with a well-defined character can in turn influence players' self-perception, by allowing them to re-conceptualize themselves temporarily as the character and selectively take on perceived attributes of the character (Klimmt et al. 2009; Yee et al. 2009).

Focalization in its original form has been defined in relation to literary written texts and non-ergodic visual texts. The study of video games raises issues that are not present in these texts. To return to the previous example of George R. R. Martin's A Game of Thrones and its adaptations, consider Game of Thrones: A Telltale Games Series (Telltale Games 2014). The Telltale Game of Thrones is a single player episodic graphic adventure game, set in the same fictional world as the novel and television series. As in the novel and television series, the video game presents an ongoing narrative from the perspective of multiple characters. The game does not directly show any private thoughts or experiences of the perspective characters, and this could be taken to indicate external focalization. On the other hand, the game regularly presents the player with choices between different actions or conversation options. This could be interpreted to mean that the character is choosing between these options, and thus the game makes us privy to their internal decision making process. Or it could be understood that these are Schrödinger choices: once the player has made a decision, they have created a version of the story in which the character acted and thought a certain way, without any indication in retrospect that their choice was in doubt. This ques- 
tion of interpretation is specific to ergodic texts such as video games (Aarseth 1997), and not accounted for in the terms of focalization drawn from narratology; different terms of reference are required for the video game medium.

This leads to a familiar and contentious question: is it appropriate to take a term that was coined to describe written texts and apply it to video games, when it is clear that the experience of playing a game can be worlds apart from the experience of reading a novel? In addressing the nature of this difference, Gordon Calleja (2009) has provided an example of how focalization remains a relevant and useful concept for describing game experiences. Calleja proposes the term alterbiography to frame how video game experiential narratives should be conceived: as a form of story generation, in which the story does not exist as an attribute of the video game artifact but is formed as a history of the player's interaction with the text. He defines alterbiography as "the active construction of an ongoing story that develops through interaction with the game world's topography, inhabitants, objects, game rules and coded physics” $(2009,5)$. Within this model of video game narrative, Calleja argues that the locus of focalization may be at the level of: a) the player's self; b) a game entity the player controls and is in some way anchored to; or c) multiple miniatures the player controls without identifying with any one of them specifically. This focalization is variable and dependent on the disposition of the player.

Perhaps the most extensive investigation of focalization for video game studies to date is that of Michael Nitsche (2005, 2008). Nitsche takes as his basis Mieke Bal's concept of focalization rather than Genette's, reasoning that Bal's adaptation is "more directly applicable to video games" $(2005,1)$ due to Bal's increased focus on visual storytelling. Accordingly, he addresses focalization predominantly in terms of visual presentation and virtual camera perspective:

"Focalization through the eyes of a virtual camera has been identified as a narrative element, which is conceptually as well as practically separable from a linear narrating 'telling voice.”' (Nitsche 2005, 5) 
Nitsche explores how a player's attention is drawn to specific elements of a video game through visual focalization techniques, such as restricted virtual camera positioning, and analyzes cases in which the visual presentation of the game world itself is altered to reflect the mental state of the focal character, as in hallucinatory dream/drug sequences.

More recently, Jonne Arjoranta (2015) described the ways in which focalization, in Genette's terms, is apparent in digital games and how this is used to create meaning-effects. In addition to Genette's three categories of external, internal, and zero focalization, Arjoranta identifies a fourth category that arises when a game's perspective and control is situated within a character that is in other respects a blank slate:

"It can be argued that video games can make use of the character-internal perspective to achieve a perspective not available in literature. This perspective is embodied in the physical perspective of the character being played but does not allow access to their mental landscape in the manner of internal focalization. In other words, the player has control over a character's actions while not having access to the character's mental landscape.” (Arjoranta 2015, 8)

Arjoranta calls this fourth category embodied focalization, and suggests that it is typically used to prompt the player to identify with the perspective character, and to view the in-game actions as their own. However, this situation raises the same question posed in the Game of Thrones example above: does control over a character's actions constitute an interior perspective, in that the player's will can be thought of as the character's will? Arjoranta says no, describing the perspective as a "behaviorist point of view” $(2015,6)$ that does not constitute internal focalization. However, in the next section I will argue that a games' control scheme and interface contain elements of internal focalization that has been previously overlooked, and which shape the player's experience to accord with that of the character.

Comparing these past utilizations of focalization in game studies calls attention to the conflicted nature of the underlying theory. Nitsche explicitly calls on "Bal's concept of focalization” $(2005,1)$, and in keep- 
ing with Bal focuses strongly on visual presentation and the virtual camera as a determinant of focalization, with relatively little attention to other game elements such as affordances for action or indeed audio presentation; in contrast, Calleja invokes "the notion of focalization proposed by Genette” (2009, 4), and correspondingly defines focalization in terms of the player's own experience of narrative situatedness rather than the game's visual perspective. Arjoranta seeks to incorporate both sides of the concept by using Genette's terminology as a basis, but focusing extensively on examples of visual (and to a lesser extent audio) perspective. Mindful of this schism in the underlying theory, this paper will focus on applying Genette's core question, “who sees?” - Or to paraphrase for the video game medium, "whose mind is the signal?”- Across multiple aspects of the game experience: visual presentation, audio presentation, affordances for action and access to private knowledge.

A final related concept that is useful when thinking about focalization is ludodiegesis. This term was coined by Dan Pinchbeck (2007) to describe consistency between the interactivity of a game environment and the player's perception of its presentation:

"Ludodiegesis is drawn from a player experience perspective based upon
observations from cognitive science. It argues that our conscious experience
of reality is formed from a subset of available information and, further, that
this natural filtering system is historically manipulated to great effect by a
large number of non-technological virtual realities such as ritual. Simply
put, we are pre-disposed to accepting reduced sets of stimuli as significantly
real.” (Pinchbeck 2007, 12)

Pinchbeck suggests that players build an understanding of a game world based on its visually suggested affordances - a concept taken from J.J. Gibson's ecological theory of visual perception (1979), which contends that the mind's perceptual system understands objects in terms of their opportunities for interaction (affordances). Pinchbeck argues that a discontinuity between expected and actual ludic affordances threatens the player's experience of ludodiegesis. The next section will explore how internal focalization has been used in the design of some games as a strategy to bridge this potential discontinuity. 


\section{3: Focalization in video games}

The focalization of a video game is apparent in its audiovisual presentation, as described by Nitsche (2005) and Arjoranta (2015), but also in its provision of characters' private knowledge and its affordances for action. Each category will be described using examples from The Sims 3, Top Spin 4, Mirror's Edge, Grand Theft Auto V, Assassin's Creed II and $Q W O P$. In each of these games, the player controls one or more defined character-avatars that are presented as having wants or needs independent of the player. Each in their own way attempts to create some kind of empathy for the character's motivations, so that the player is motivated to do things specifically because their character would want to do so. This makes them well suited to illustrate the presence of internal focalization in the design of video games.

\section{1: Audiovisual presentation}

Genette (1980) measured focalization with a simple yardstick: when the audience knows less than a character about the character's experiences, there is external focalization. When the audience knows the same as the character, there is internal focalization. When the audience knows more, there is zero focalization. On these criteria, perhaps the most common expression of internal focalization in video games is the provision of private knowledge through an extradiegetic heads-up display (HUD).

Such a HUD is a central feature of The Sims 3, a life simulation game viewed from a third person perspective, in which the player controls one or more virtual people ("Sims") in their daily life. Each Sim has a name and a characterization, expressed in such qualities as life goals, favorite foods, music and colors, and personality traits such as "AbsentMinded”, "Loves The Cold” and "Eco-Friendly”, all of which influence their behavior.

The player is made privy to the traits of their family of Sims through the HUD, which also shows such measures as how hungry, energetic and 
clean the Sim feels at that moment. This information is only available for Sims within our control, which roots the focalization as internal to those Sims, giving the player greater understanding and therefore sympathy for them as characters, alongside the alterbiographical empathy of being in partial control of their actions. The game also indicates what Sims are thinking, in the form of thought bubbles that appear at times above a Sim's head containing an icon - for example, a gravestone, from which the player can infer the Sim is thinking about death. ${ }^{3}$ The HUD and thought bubbles are hypermediate elements (Bolter and Grusin 1999), in that they are not implied to exist in the video game as objects that appear real to the characters. Rather, they reflect the game characters' private experiences and desires.

Such hypermediate elements are standard in the sports games genre, and act as a type of ability-based inner focalization signal, representing characters' private intuitive knowledge in a dynamic fashion. Consider Top Spin 4, a tennis game in which the player controls a professional tennis player on the Grand Slam circuit, and includes some real life players such as Roger Federer and Serena Williams. The player alternates between managing their character's career - choosing tournaments to play in and training programs to undertake through a set of menus and controlling their character on the court, from a third person view that replicates the standard behind-the-baseline camera angle of televised tennis matches.

3. Characters in some story-driven video games can be heard to vocalize their thoughts to themselves for the benefit of the player; both Mirror's Edge and Grand Theft Auto V feature examples. This provides a simple test case distinction: if the character's thoughts are audible directly without speech, internal focalization is implied, but if the character is speaking aloud, internal focalization is not implied. 


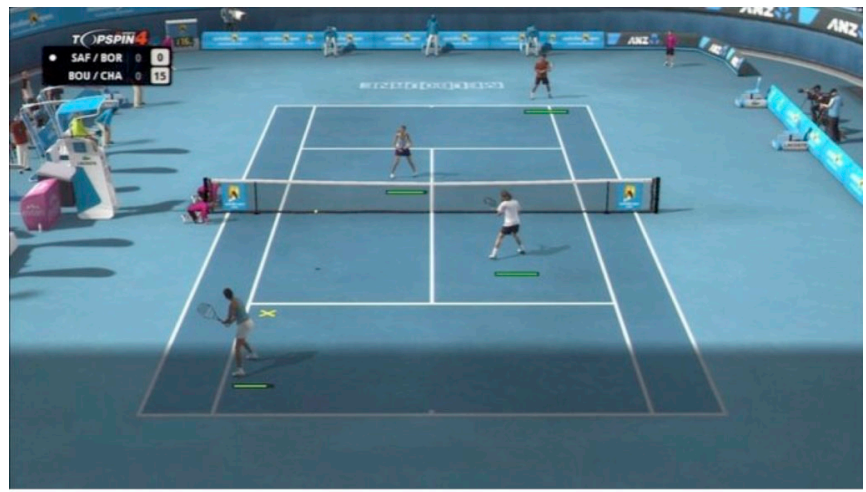

Figure 1: A yellow cross marks the landing point of an incoming ball in Top Spin 4 (2K Czech 2011).

During the match play mode, when the player is facing an incoming shot, a yellow cross appears to mark where the ball will land (see Figure 1). This allows the player to anticipate the shot and move their avatar into position for a return shot. The marker is not a purely ludic device devoid of narrative or ludodiegetic significance: it serves to align the player's experience of Top Spin 4 matches with the experience of being a professional tennis player. A player may not have the ability to quickly calculate the landing point of an approaching tennis ball as it is in flight, but the character they are controlling would be expected to. By visualizing situational assessments that the character (but not the player) would intuitively make, Top Spin 4 communicates to the player a subjective experience of being the character, rather than a "transparent" observation of the game space. In this sense, the presentation has an element of internal focalization.

That this information is a subjective judgment is suggested by the treatment of line-balls. Shots that will land outside of the court are not given a bounce marker - they are not presented as a target, just as an experienced tennis player judges not to hit a ball that is headed out of bounds. However, shots that are on a trajectory to bounce very close to the outside boundary - those that are "too close to call" until they land - are 
also not given a bounce marker. This mirrors the limits of a real professional tennis player's ability to accurately predict a shot; in this situation, the character could not know for certain whether the ball would land in the court, and correspondingly, neither does the player.

Mirror's Edge goes much further still to give players the experience of an unfamiliar mind in action (Allison 2010). ${ }^{4}$ It is presented in first-person perspective and designed around the experience of free running (parkour) in an urban environment. The perspective character, Faith Connors, is a courier who transports illegal packages and information across the rooftops of an unnamed modern city. Unlike The Sims 3 and Top Spin 4, where degrees of internal focalization are communicated through extradiegetic elements, Mirror's Edge features a visual representation of the game world itself that is specific to the private, subjective mental models of Faith.

There are two primary visual styles in Mirror's Edge: one in cut-scenes and another in gameplay. During cut-scenes, the perspective is that of a third-person camera, and the visual presentation is relatively stylized, with a cartoon-like appearance. Objects are picked out in simple blocks of flat, bright, cel-shaded color. Cut-scenes feature frequent cuts between "camera positions" in a traditional cinematic style. Certain cutscenes replace the bright colors and clean outlines with a blurrier, unfocused appearance, together with a voice-over narration by Faith speaking in past tense, which together indicate that these are Faith's slightly hazy recollections of past events. During gameplay, the perspective is first-person through the eyes of Faith, and the visual style is relatively photorealistic, with objects modeled and textured in detail. The only extradiegetic interface is a tiny white or blue dot at the center of the screen; this creates a highly immediate experience for the player, as it avoids elements such as a HUD that bring attention to the mediated nature of a video game interface (Bolter and Grusin 1999).

4. Calleja cites Mirror's Edge as a prime example of a video game that evokes an alterbiography of self, "where players interpret the events happening in the game as happening to them." (2009, 4; emphasis in original) 
However, Mirror's Edge does not show an objective, "transparent" visual representation of its game world. Rather, it represents the game environment in terms of Faith's attention to it, in a stylized visual presentation referred to as Runner Vision. Most objects in the game world are depicted as blank white shapes, including some that would ordinarily be colorful, such as fire hose reels and leafy pot plants (see Figure 2); specific objects are colored, using a limited palette in which each color has an associated meaning for Faith. Faith alludes to this schema in a voiceover narration in the opening cut-scene: "Runners see the city differently than regular people and understand the natural flow."

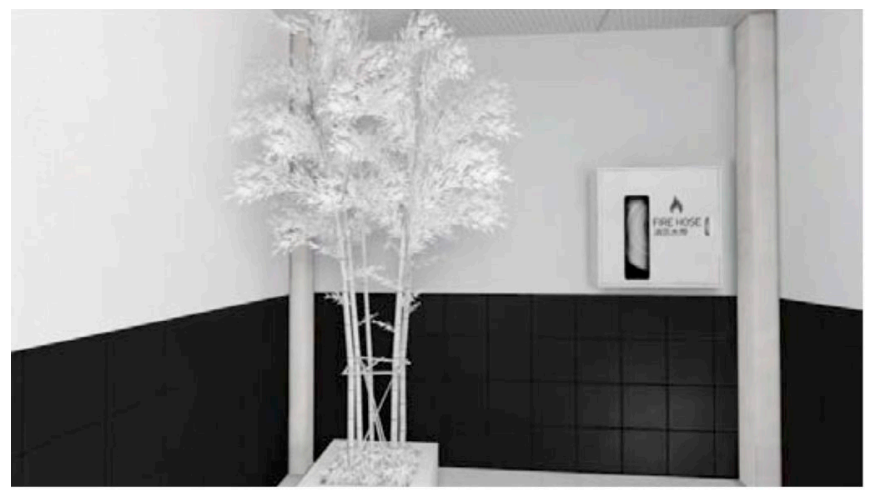

Figure 2: A pot plant and a fire hose box in Mirror's Edge (EA Digital Illusions CE 2008), colored white due to their perceived lack of relevance in the Runner Vision schema.

White objects represent the visual ground, in Gestalt perceptual terms (Wagemans et al. 2012). These are the things that are visible to Faith, but form the background to her attention. Floors, walls and ceilings are typically white, including the entirety of most buildings outside Faith's attentional pathway. Plants and fire hoses are white because, although they have a function, it is not relevant to Faith's priorities. This selective whitewashing of the perceptual ground shows a kind of attentional blindness in which the relevance of an object is categorized according to the 
character's perception of its ability to support continued movement - its affordances (Gibson 1979).

The color red signifies an object that facilitates fast traversal of the environment. For example, a red box can be jumped from to leap over a fence, and a red overhead pipe can be swung from to reach a distant ledge. Some red objects act as landmarks to orient the player towards their goal, such as a large red logo on a building that is Faith's goal to reach. Often, objects fade from white to red only as they move into Faith's zone of attention; for example, as a helicopter descends towards Faith, its landing skids change from white to red when it is close enough for Faith to jump up and grab on to them. Thus Mirror's Edge approaches the problem of ludodiegesis (Pinchbeck 2007) from the angle of focalization. Rather than only including objects in the game environment that provide ludic affordances, Mirror's Edge presents the ability to use objects as a function of the perspective character's interest in them.

The color blue marks objects that tend to slow Faith down or stop her progression. For example, a blue fence is likely to have a sheer drop behind it, and a blue staircase is likely to be slow for Faith to climb. Notably, the police forces that pursue Faith are referred to as "blues", and wear dark blue uniforms. 


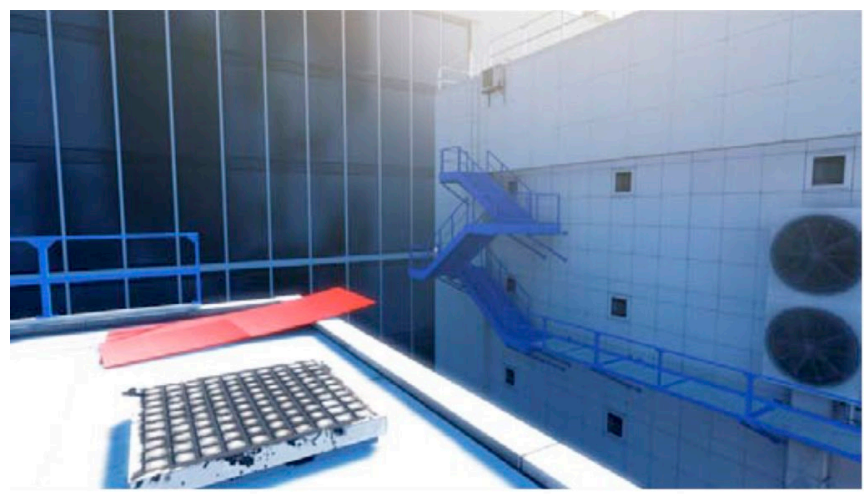

Figure 3: A rooftop in Mirror's Edge (EA Digital Illusions CE 2008). The ramp affords a jumping-off point, so is red. The staircase is blue, indicating that it will be slow to climb.

The color black represents danger. All firearms are jet black, as are the uniforms of the private security forces that constitute the more heavily armed and dangerous enemies Faith encounters; in general, the more physically dangerous the enemy or armament, the greater its surface area of black. Faith is herself dressed partly in black, appropriate to her abilities as a skilled hand-to-hand fighter.

The black theme ties in with the way that Mirror's Edge represents Faith's health. There is no extradiegetic health bar; any damage Faith takes is represented by the visual field progressively de-saturating and darkening. Simultaneously, the game audio fades down in volume and becomes muffled. When Faith loses consciousness, the screen fades completely to black and the game sound is silenced. The player is cut off from the game world, demonstrating that Faith's consciousness is the player's conduit into that world. This is unlike many first person games, which continue to show an image of the game environment after the player-controlled avatar dies (see for example Halo 4, 343 Industries 2012).

In both Mirror's Edge and Top Spin 4, it is possible to turn off some of the visual indicators described above. This increases the difficulty for the 
player, but it also shifts the focalization away from the perspective of the expert character and towards a more neutral external focalization, as the player is forced to replace the character's mental patterns with his or her own. If the player's abilities are inadequate to the task, this creates a discontinuity with the experience of being an expert tennis player or free runner.

In Grand Theft Auto $V$, the player alternates control between three quite different characters: Michael De Santa, a wealthy, white, middle-aged father of two fighting a failing marriage, anger management issues and an existential crisis; Franklin Clinton, a cool-headed young black man seeking to escape his poor urban neighborhood and its cycles of petty crime and incarceration; and Trevor Philips, a middle-aged violent psychopath portrayed according to "white trash" stereotypes, with a strong entrepreneurial drive. These dissimilarities are not represented in the presentation of the game world, which appears the same no matter whom the player is controlling. However, specific events effect changes in the visual presentation that imply a degree of internal focalization.

Each of the three perspective characters has a unique ability. When the ability is activated, the visual presentation of the game world changes for a short period of time in a way that reflects the character's mental state. Franklin's ability depicts something resembling a flow state (Csikszentmihalyi 1990), in which the visual field tints to a cool shade of blue and time appears to slow down, allowing the player to calmly steer a vehicle through otherwise difficult maneuvers. In contrast, Trevor's special ability depicts a "red mist" state, in which the visual field tints to a sanguine red and Trevor gains a damage boost and a level of imperviousness to injury, allowing the player to rampage through a gunfight without heed to danger. These effects bring the player's experience in line with the depiction of their character: Franklin as a cool-headed and adept getaway driver, Trevor as a callous hothead with little fear of danger.

A further element of internal focalization in Grand Theft Auto V appears 
during sequences in which the perspective characters hallucinate. ${ }^{5}$ In one example, Michael imagines that he is abducted by aliens and dropped from their spacecraft above a neon-lit vision of his home city; as he falls slowly towards it, he hears reverberating echoes of his own selfdoubts ("I always thought I was the good guy”; "It's like I'm two different people”) and criticism from others (his daughter yelling "You ruined my life!"; his wife saying "You are nothing but a murdering, cheating hypocrite!”). Even after Michael's senses return to his "reality”, the visual presentation retains an unfocused, flared-light quality that represents his visual perceptions gradually returning to a normal state. In these sequences, the audiovisual presentation of the game world is comprehensively altered so that what the player is seeing and hearing corresponds with what the character is seeing and hearing. The virtual camera perspective is external, so the player does not see through the characters' eyes, but they do see the game world the way that the character does.

Video games, like films, also use music to illustrate a character's private experience, often in response to changes in the environment. For example, in Mirror's Edge, being pursued by an enemy triggers a swell of loud, high-tempo music, representing (and attempting to replicate in the player) Faith's surge of adrenaline. Music in video games can be considered an element of internal focalization when it communicates or emphasizes a character's emotional state.

\subsection{Affordances}

Law professor and political reform advocate, Lawrence Lessig (2000), has argued that the way in which a network system is designed should be considered as a question of values, because the programming is a powerful determinant of what people can and cannot do within the network summarized as "code is law". 
The same is true of video game characters: their values are constrained by their programming. The player may control Franklin, Trevor and Michael in Grand Theft Auto V, but is only free to enact their lives within a prescribed set of behaviors. The scripted story of each character suggests that these are the only kinds of actions they see as available to them - we hear each one struggle with (or, in Trevor's case, enjoy) a belief that their only options in life center around criminal behavior - and the player perceives this directly, through the limited set of actions they are able to direct the characters to take, which are almost exclusively violent and criminal in nature. The player defines the character by their choices of behavior, but the game designer establishes the possibility space within which the character may be so defined. Therefore it is valid to say that the character is violent and criminally disposed, rather than this being a reflection of the nature of the player that controls them. Code is character.

As has been described above, each of the perspective characters in Grand Theft Auto $V$ has a unique ability, and these abilities reflect attributes of their personality as they are presented in the scripted dialogue: Franklin is cool and focused, Trevor is a hothead. Beyond this, however, the actions available for each character are identical. The player thus experiences these characters, "from the inside" as it were, as entities with nearly interchangeable values; each one equally ready to hijack a car at the press of a single button, or fire a gun on a crowded street at the pull of a trigger, and equally uninterested in, say, cooking up a meal when standing in their kitchen. It is a game with three perspectives, but not three points of view.

The Sims 3 goes some way towards establishing a different action set for each character by limiting action options according to a combination of traits and dynamic statuses. Each Sim may have up to five personality traits, selected from a larger list, each of which will modify their actions or responses to events: an "Eco-Friendly" Sim will take showers faster than other Sims, and will gain a positive mood when gardening; an "Insane" Sim can talk to themself to boost their level of social ful- 
fillment; a "Hydrophobic" Sim will avoid swimming pools. Behavioral options are also affected by dynamic statuses, such as the strength of a relationship, which determines whether one Sim can choose to kiss another. All together, these factors establish distinctive personality frameworks so that the player understands the distinct private mental boundaries of their Sims.

Although it has only one perspective, Mirror's Edge once again provides a strong impression of internal focalization through its affordances. Simply learning the control scheme for Faith conveys to the player that her expertise and attention is directed towards efficient movement: there are nine control inputs for movement and orientation, one to interact with objects in the environment (most of which open up new passages), one to focus (slowing game time $a$ la Franklin's ability in Grand Theft Auto $V$ ), and only two for combat - one of which is a disarming move, and the other of which is used as often for slamming open doors as for fighting. Unlike most first-person games that involve shooting, there is no ability to switch between guns, or to reload; the button to pick up a weapon also throws it away at a touch, or Faith will discard it automatically once the magazine is empty, or if she needs her hands free for an acrobatic movement.

To the player, Faith feels most potent and adept when she is moving freely. Picking up a weapon makes the player feel paradoxically less powerful, in part because Faith's foot speed slows significantly and in part because aiming the weapon is a more manual, less context-sensitive action than movement. This creates for the player a reluctance to engage in combat and a frustration when sighting opponents - which are concordant with the experience of a character whose goals and motivations do not involve violence. Although many critics cited the frustration of combat as a flaw in the game design,9 Ian Bogost proposed that it should instead be read as an insight into the experience of Faith: "Instead of reading the game's combat system as a weakness, we can understand Mirror's Edge instead as a game about a character's weakness.” (2008, 4) 
The operations involved in movement provide a more finely tuned experience of the character, which can be seen most clearly in comparison to other video games in which the player controls an athletic runner. In Mirror's Edge, the primary movement commands are lightly contextually sensitive: the "up" command will cause Faith to jump, or vault over a low object, or launch into a leap from a low step, or run for a short distance along a wall, if these objects are in the correct position when the player presses the button; similarly, the "down” button will cause Faith to crouch, or slide under a suspended object, or tumble through the landing of a jump. However, the player must orient Faith perfectly and activate her controls with precise timing, or risk falling to their death; the experience is one of competence in a difficult, demanding and dangerous task.

It is informative to contrast the control scheme in Mirror's Edge with two video games that were published at around the same time: Assassin's Creed II and QWOP. Both are likewise centrally concerned with the task of fluent movement, but feature control schemes that provide very different experiences of their central characters.

In Assassin's Creed II, the player also controls a free runner - Ezio Auditore - traversing city rooftops at speed, with even more contextually dependent controls. By holding down a single button, the player must only point Ezio towards a series of handholds and he will climb, leap and shimmy his way up any obstacle; holding down a second button will cause him to do all of this faster and add flying leaps. The close clustering of buildings and surfeit of handholds on the Renaissance architecture means leaping blindly into space is often rewarded with a safe landing, and even a hard landing is rarely fatal. In contrast to Mirror's $E d g e$, the player's experience of Ezio is a nearly effortless mastery of the environment in which timing is unimportant and the need for precision is comparatively generous. This makes the player's experience accord with the external portrayal of the character, as an impulsive, dashing optimist with little sense of danger. 
At the other end of the scale is $Q W O P$, in which the player controls an Olympic sprinter named Qwop, visually modeled on Carl Lewis (see Figure 4). QWOP is notable for its extremely manual control scheme. The keyboard letters Q and W lift Qwop's right and left thighs, and the letters $\mathrm{O}$ and $\mathrm{P}$ lift Qwop's left and right calves. The objective is to reach the end of a one hundred meter running track without falling over. In contrast to Mirror's Edge and Assassin's Creed II, QWOP contains no context sensitivity in the controls; Qwop will not even maintain his own balance. Extensive practice is needed to move Qwop without him falling onto his face or flipping over backwards. The experience is disorienting, and intentionally distant from the expectations of how it feels to be an Olympic athlete, as the game's creator, Bennett Foddy, expressed in an interview:

"Friends told me I should make the character in QWOP a drunk guy trying to get home from the pub, rather than an Olympic runner. But I think if I had done that it would have felt like the point of the game was to stumble awkwardly, rather than run smoothly. Most of the value in QWOP, for me, comes from the fact that you're trying — and usually failing — to run like a normal person. Making him an Olympic athlete sets up a particular context where running fast is expected, and this maximizes that feeling of playful frustration when you fall over on your head.” (Cook 2011)

This frustration comes with a sense of being locked out of the mental functions that normally make walking and balancing automatic processes. Unlike Faith in Mirror's Edge and Ezio in Assassin's Creed II, Qwop's presumed expertise at running is locked away from the player. Qwop remains an enigma whose inner world we have only the tiniest sliver of access to. 


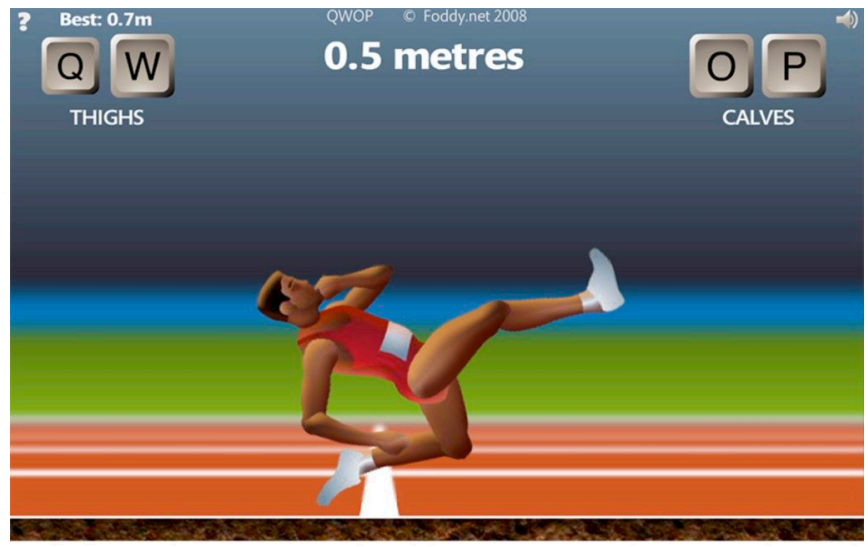

Figure 4: In QWOP (Foddy 2008), the simple action of walking is made difficult by controls that map each leg muscle to a different key.

\section{3: Discussion and conclusion}

Video games in which a player directly controls a character have opportunities to convey the character's subjective experience and ways of thinking to the player. Whether the audiovisual style is photorealistic or stylized, the presentation of the game environment can be suggestive of the subjectivity of the character that views it - as is commonly seen in a few specific patterns, such as hallucinatory sequences. The ludic affordances of such video games typically convey a great deal about the character's nature, goals and mental models, as well as their abilities. In doing so, the player's own perspective and way of thinking is shaped according to what is required to operate the video game. This gives game designers a powerful opportunity to present a diversity of perspectives and open up particular desired experiences for the player.

This paper has proposed an appropriation and adaptation of Gérard Genette's concept of focalization for video game studies as a framework for understanding how video games allow their players access to different ways of seeing and relating to the virtual environment. Nitsche, Calleja and Arjoranta's applications of focalization in video game stud- 
ies have been reviewed, as well as Pinchbeck's related concept of ludodiegesis. These applications demonstrate the utility of focalization as a framework for video game studies, but do not cover the full scope for analysis possible. Examples drawn from various video games have shown that audiovisual presentation, access to private knowledge and ludic affordances all have the potential to communicate the inner, subjective experience of a character to the player. Focalization can be a useful concept for game designers and critics to talk about the framing of a video game's presentation as internal or external to the character's experience, and to consider the effects of adjustments to this framing.

Video games do not present a strictly narrative storytelling experience in the manner of the literary and filmic texts that form the basis of Genette and Bal's idea of focalization. This paper has addressed how the ludic affordances of video games complicate a simple reading of focalization, but this deserves further consideration with regards to the alterbiographical nature of video game narratives.

This paper has sought to present a variety of examples to demonstrate the wide potential for application of focalization within video game studies. However, an ideal case study has not been addressed: a video game or virtual world in which multiple characters are controllable, and the presentation and ludic affordances of the game space are substantially different for each one. This would provide rich soil for an analysis of the variations between viewpoints and the effect of these on the player experience.

A final question that requires further study is whether changes to focalization influence a player's self-perception. Klimmt et al. (2009) have advanced the theory that players identify with their game-world avatars, and selectively adjust their self-concept to reflect characteristics of its character. It is not yet understood how changes to the focalization of the experience may influence this effect. For example, both Mirror's Edge and Top Spin 4 have options to increase the difficulty of the game by removing some of the visual information that conveys the character's 


\section{ToDiGRA}

private knowledge (Runner Vision in Mirror's Edge and bounce markers in Top Spin 4). In so doing they force a substitution of the player's own mental processes for those of the character, shifting the game to a more external focalization. Further empirical research is suggested to understand how this affects the player's identification with the character and the consequences this may have for the player's experience and self-perception.

\section{References}

2K Czech. 2011. Top Spin 4 [Multiple Platforms]. 2K Sports, Novato, CA.

343 Industries. 2012. Halo 4 [Xbox 360]. Microsoft Studios, Redmond, WA.

Aarseth, E. J. 1997. Cybertext: Perspectives on Ergodic Literature. Baltimore, Md.: Johns Hopkins University Press.

Allison, F. The videogame as prosthetic imagination: Immersion in Mirror's Edge. Unpublished honors thesis, RMIT University, 2010.

Arjoranta, J. 2015. "Narrative Tools for Games: Focalization, Granularity, and the Mode of Narration in Games.” Games and Culture 1555412015596271.

Bal, M. 2009. Narratology: Introduction to the Theory of Narrative. Toronto: University of Toronto Press.

Benioff, D., and Weiss, D. B. 2011. Game of Thrones. [TV programme] HBO.

Bogost, I. 2015. "Persuasive Games: Windows And Mirror's Edge”. Gamasutra. Available at http://www.gamasutra.com/view/feature/ 132283/persuasive_games_windows_and_.php (accessed Jan. 2015). 
Bolter, J. D. and Grusin, R. 1999. Remediation. Cambridge, Mass.: MIT Press.

Calleja, G. 2009. "Experiential Narrative In Game Environments”. In DiGRA '09 - Proceedings of the 2009 DiGRA International Conference: Breaking New Ground: Innovation In Games, Play, Practice And Theory. Brunel University, London. Available at http://www.digra.org/wpcontent/uploads/digital-library/09287.07241.pdf (accessed Jan. 2015).

Carter, M., Gibbs, M. and Arnold, M. 2012. “Avatars, characters, players and users: multiple identities at/in play." In Proceedings of the 24th Australian Computer-Human Interaction Conference, pp. 68-71. ACM.

Cook, S. 2011. “The Last and Final Word: Bennett Foddy”. Blog. Quote Unquote. Available at http:/quote-un-quote.tumblr.com/post/ 9764185738/interview-indiedev-bennett-foddy (accessed Jan. 2015).

Csikszentmihalyi, M. 1990. Flow: the Psychology of Optimal Experience. New York: Harper \& Row.

EA Digital Illusions CE. 2008. Mirror's Edge [Multiple Platforms]. Electronic Arts, Redwood City, CA.

Firaxis Games. 2010. Sid Meier's Civilization V [PC]. 2K Games, Novato, CA.

Foddy, B. 2008. QWOP [Online Flash]. Available at https://www.foddy.net/Athletics.html (played Jan. 2015).

Genette, G. 1980. Narrative Discourse: An Essay In Method, translated by Jane E. Lewin. Ithaca, N.Y.: Cornell University Press.

Genette, G. 1988. Narrative Discourse Revisited, translated by Jane E. Lewin. Ithaca, N.Y.: Cornell University Press.

Gibson, J. J. 1979. The Ecological Approach To Visual Perception. Boston: Houghton Mifflin. 
Jahn, M. 2010. “Focalization”. In Herman, D., Jahn, M., and Ryan, M. (Eds.) Routledge Encyclopedia Of Narrative Theory, pp. 173-177. London: Routledge.

Hyman, I. E., Boss, S. M., Wise, B. M., McKenzie, K. E., and Caggiano, J. M. 2009. "Did You See The Unicycling Clown? Inattentional Blindness While Walking And Talking On A Cell Phone”. Appl. Cognit. Psychol. 24 (5): 597-607.

James, W. 1892. Psychology: Briefer Course. New York: Henry Holt and Co.

Klimmt, C. Hefner, D., and Vorderer, P. 2009. “The Video Game Experience As 'True' Identification: A Theory Of Enjoyable Alterations Of Players’ Self-Perception”. Communication Theory 19 (4): 351-373.

Lessig, L. 2000. “Code Is Law: On Liberty In Cyberspace”. Harvard Magazine. Available at http://harvardmagazine.com/2000/01/code-islaw-html (accessed Jan. 2015).

Martin, G. R. R. 1996. A Game Of Thrones. New York: Bantam Books.

Metacritic. 2015. “Mirror’s Edge (2008)”. Available at http://www.metacritic.com/game/xbox-360/mirrors-edge-2008/critic-reviews (accessed Jan. 2015).

Mojang. 2009. Minecraft [Multiple Platforms]. Mojang, Stockholm, Sweden.

Most, S. B., Simons, D. J., Scholl, B. J., Jimenez, R., Clifford, E., and Chabris, C. F. 2001. "How Not To Be Seen: The Contribution Of Similarity And Selective Ignoring To Sustained Inattentional Blindness”. Psychological Science 12 (1): 9-17.

Nitsche, M. 2005. “Focalization in 3D Video Games”. In Digital Proceedings of Future Play, Lansing, MI October 13-15. Available at 
http://dm.lcc.gatech.edu/ nitsche/download/Nitsche_Focalization_05.pdf (accessed Jan. 2015).

Nitsche, M. 2008. Video Game Spaces. Cambridge, Mass.: MIT Press.

Papale, L. 2014. "Beyond Identification: Defining the Relationships Between Player and Avatar”. Journal Of Games Criticism 1 (2). Available at http://gamescriticism.org/articles/papale-1-2/ (accessed Jan. 2015).

Pinchbeck, D. 2007. "Counting Barrels in Quake 4: Affordances and Homodiegetic Structures in FPS Worlds”. DiGRA '07 - Proceedings of DiGRA 2007 Conference: Situated Play. The University of Tokyo. Available at http://www.digra.org/wp-content/uploads/digital-library/ 07311.20364.pdf (accessed Jan. 2015).

Rockstar North. 2014. Grand Theft Auto V [Multiple Platforms]. Rockstar Games, New York, NY.

Silicon Knights. 2002. Eternal Darkness: Sanity’s Requiem [GameCube]. Nintendo, Kyoto, Japan.

Telltale Games. 2014. Game of Thrones: A Telltale Games Series [Multiple Platforms]. Telltale Games, San Rafael, CA.

The Sims Studio. 2009. The Sims 3 [PC]. Electronic Arts, Redwood City, CA.

Ubisoft Montreal. 2012. Far Cry 3 [Multiple Platforms]. Ubisoft, Paris, France.

Ubisoft Montreal. 2009. Assassin's Creed II [Multiple Platforms]. Ubisoft, Paris, France.

Wagemans, J., Elder, J. H., Kubovy, M., Palmer, S. E., Peterson, M. A., Singh, M., and von der Heydt, R. 2012. “A Century Of Gestalt Psychol- 
60 ToDiGRA

ogy In Visual Perception: I. Perceptual Grouping And Figure-Ground Organization”. Psychological Bulletin 138 (6): 1172-1217.

Yee, N., Bailenson, J. N., and Ducheneaut, N. 2009. “The Proteus Effect: Implications Of Transformed Digital Self-Representation On Online And Offline Behavior”. Communication Research 36 (2): 285-312. 